\title{
Accidental Burn in a Neonate in Neonatal Intensive Care Unit: What Could be the Cause?
}

\author{
Poonam Singh $^{1}$ - Jaya Upadhyay ${ }^{1} \cdot$ Sriparna Basu ${ }^{1}$ \\ Received: 8 January 2020 / Accepted: 12 March 2020 / Published online: 20 March 2020 \\ (C) Dr. K C Chaudhuri Foundation 2020
}

To the Editor: Iatrogenic burn injuries are rarely reported in neonates. A 3-d-old neonate with meconium aspiration syndrome was being mechanically ventilated in a neonatal intensive care unit (NICU). His diaper was kept open as he had perineal rash. Dry gauze pads were placed under buttocks to provide a soft surface. During an episode of desaturation, endotracheal suctioning was performed. After the procedure was over, while changing the diaper, the care-giving nurse suddenly noticed that the gauze pads and diaper have caught flames. Though she immediately threw away the burning materials, the infant sustained first-to-second degree burns over the buttocks and posterior surface of thighs. Burn management was started immediately in consultation with plastic surgeons. Event investigation by electrical and bio-medical engineers found that the radiant warmer and other equipment attached with the infant (ventilator, syringe pumps, multi-para monitor) were undamaged and fully functional. The electrical circuits of NICU were also intact. Incident analysis revealed that after suctioning, oxygen tube used to provide free-flow oxygen during suctioning was left open. The nurse rubbed her hands with alcohol based hand rub (ABHR) before and after suctioning. Friction of hand-rubbing and subsequent touching of polyethylene surface of diaper probably generated static electricity by triboelectric effect [1]. The prerequisites for fire i.e., an ignition source (electrostatic discharge), fuel (alcohol vapors) and oxygen, probably resulted in fire accident with combustion of gauze pads and diaper.

Previous reports linked ABHR with fire-accidents in operation-theatres using electrocautery [2]. In healthcare set-

Sriparna Basu

drsriparnabasu@rediffmail.com

1 Department of Neonatology, All India Institute of Medical Sciences, Rishikesh, Uttarakhand 249203, India ups, fire-accidents triggered by high voltage electrostatic discharge generated by routine activities such as hand-rubbing while wearing polyester gowns, have been reported $[3,4]$. Ringing of mobile phone while handling the car fuel-tank has also been associated with accidental fire-incident [5]. Mobile phone was not present near the place of fire-accident in our case.

We speculate that avoidance of hand-rubbing using ABHR under the warmer, complete drying of hands before touching any polyethylene/polyester/metal surface and closure of oxygen supply immediately after use can avoid such an incident. The neonate made complete recovery and was discharged.

\section{Compliance with Ethical Standards}

Clearance of Institute Ethics Committee and informed consent from parents was taken for publication.

Conflict of Interest None.

\section{References}

1. Static electricity. Available at: https://www.explainthatstuff.com/ how-static-electricity-works.html. Accessed 17 February 2020.

2. Spigelman AD, Swan JR. Skin antiseptics and the risk of operating theatre fires. ANZ J Surg. 2005;75:556-8.

3. Bryant KA, Pearce J, Stover B. Flash fire associated with the use of alcohol-based antiseptic agent. Am J Infect Control. 2002;30:256-7.

4. Jover-Sáenz A, Barcenilla-Gaite F, López-Salcedo R, CastellanaPerelló D. Spontaneous flash fires during use of alcohol-based hand rubs. Enferm Infecc Microbiol Clin. 2015;33:503.

5. Potokar T, Ross AD, Clewer G, Dickson WA. Mobile phones-a potential fire hazard? Burns. 2003;29:493-4.

Publisher's Note Springer Nature remains neutral with regard to jurisdictional claims in published maps and institutional affiliations. 